\title{
A Case of Streptozocin Monotherapy for Unresectable Duodenal Neuroendocrine Tumor G2
}

\author{
Koji Miyagawa Yudai Nakabayashi Yosuke Ishihara Momoko Todo \\ Nobuaki Fuji \\ Saiseikai Kyoto Hospital, Kyoto, Japan
}

\section{Keywords}

Neuroendocrine tumor · Duodenal tumor · Streptozocin

\begin{abstract}
Background: Duodenal neuroendocrine tumors (NET) are rare, and few reports have demonstrated the effectiveness of chemotherapy for duodenal NET, with not many other treatment options available. Here, we present a case of unresectable duodenal NET G2 that was effectively treated with streptozocin (STZ) monotherapy. We also perform a literature review. Case Summary: A 57-year-old man presented with multiple lymph node metastasis, liver metastasis, and bone metastasis that occurred after the primary resection of the duodenal NET G2. His long-term survival was obtained; the duration of stable disease exceeded 1 year and 6 months following STZ monotherapy. In addition, his CA 19-9 levels, which previously were increasing, normalized following treatment. Conclusion: To our knowledge, no study has reported the effectiveness of STZ monotherapy for duodenal NET. Our findings demonstrate that for unresectable duodenal NETs, STZ should be first administered as a high volume/single dose to stabilize the disease. However, if the disease progresses, a combination therapy may be effective in obtaining a long-term prognosis of the patient. Furthermore, CA19-9 levels may be an effective factor for determining the therapeutic effect of STZ in NET with other metastases.
\end{abstract}




\section{Case Reports in Oncology}

\section{Introduction}

Neuroendocrine tumor (NET) is a rare disease [1], originally considered to progress slowly with a low grade. However, in recent years, studies have reported the increased occurrence of NET in the US, Europe, and Japan [1-4].

The first choice of treatment for NETs is surgical resection; however, studies have reported that $40-95 \%$ of patients have distant metastases when NET is detected [2].

For this reason, multidisciplinary treatments, including anti-tumor agents, are often required. In Europe and the US, streptozocin (STZ) chemotherapy has been the key treatment for NET for $>30$ years, and its concomitant use with 5 -fluorouracil (FU) and doxorubicin (DOX) is the current standard treatment choice. However, the treatment response rate of duodenal NET is lower than that of pancreatic NET, and the number of reports on duodenal NET in Japan is low [5-14]. In Japan, STZ was approved in 2015. As in our case, STZ is used as a single agent for treating duodenal NET, although cases with its significant effect have rarely been reported in Japan and other countries $[4,6]$.

Octreoscan has been used for detecting the metastasis and recurrence of NET. However, in Japan, hospitals wherein indium-111-labeled pentetreotide can be performed are limited, and frequently performing Octreoscan is not possible at our hospital. Furthermore, the measurement of chromogranin A has not been approved in Japan. Here, we report about a case of unresectable duodenal NET G2 that was effectively treated with STZ monotherapy and also perform a literature review.

\section{Case Report}

A 57-year-old man underwent pancreatoduodenectomy for duodenal bulb NET (G2) (T1 N1 M0 Stage IIIb) in December 2015 (Fig. 1). However, multiple liver metastasis was observed 6 months after the surgery. Therefore, TACE (lipiodol) was performed, which was ineffective, leading to disease progression. Next, everolimus was administered; however, CA 19-9 levels elevated after 6 months of administration, and multiple liver, lymph node, and bone metastasis was confirmed by an octreotide scan. The disease was judged to PD (Fig. 2a). In May 2017, STZ monotherapy $\left(1,000 \mathrm{mg} / \mathrm{m}^{2}\right.$; weekly administrations) was initiated. The CA 19-9 levels decreased after the third course and normalized after the fifth course. One year later, an octreotide scan showed a stable disease (Fig. 2b). However, 1 year later, because CA 19-9 levels increased, the STZ dose was increased to $1,500 \mathrm{mg} / \mathrm{m}^{2}$, after which the levels normalized again for the second time (Fig. 3). The STZ dose could be increased to $1,500 \mathrm{mg} / \mathrm{m}^{2}$ because the patient could tolerate the increased dose. The progression-free survival of the patient exceeds 1 year and 6 months, with STZ monotherapy ongoing for the patient (56 courses administered).

Patient consent was obtained, and the study was approved by the ethics committee of our hospital. 


\section{Case Reports in Oncology}

Case Rep Oncol 2019;12:14-21

DOI: $10.1159 / 000496017$

(c)

(C) 2019 The Author(s). Published by S. Karger AG, Basel www.karger.com/cro

Miyagawa et al.: Streptozocin Monotherapy for Duodenal NET

\section{Discussion}

The 5-year survival rate of patients with gastrointestinal NET with liver metastasis is 56$83 \%$, and appropriate control of liver metastatic lesions may lead to better and longer prognosis [8]. Currently, NET is treated with STZ chemotherapy. The response of pancreatic NET to STZ via GLLUT 2 of the pancreatic islets of Langerhans is considered to be the mechanism of action of STZ [15]. Because GLUT 2 is distributed in the small intestine, STZ is expected to be effective for gastrointestinal tract NETs [16]. However, a meta-analysis revealed that the response rate of gastrointestinal tract NET was lower than that of pancreatic NET (odds ratio $0.35 ; 95 \%$ confidence interval $0.18-0.66$ ) [17].

Our case had two main findings. The first finding was that the administration of STZ alone had no severe side effects, and long-term administration is recommended only when effects are observed. A previous study compared the side effects observed in the STZ monotherapy group and the combination group. Nausea and vomiting were observed in $80 \%$ of cases in both groups. Regarding myelosuppression, the incidence of leukopenia and thrombocytopenia was $5 \%$ in the monotherapy group, that of leukopenia was $73 \%$ in the combination group, and that of thrombocytopenia was $27 \%$ in the combination group [18].

In our case, nausea and myelosuppression were not observed. Although he complained about awakening in the night after the tenth course, the complaint spontaneously resolved with no treatment required. STZ has been continuously administered for more than a year. Moreover, the patient could continue treatment and have an active social and work life.

A PubMed search for "NET" and "STZ" revealed 10 cases. Among them, two cases reported STZ monotherapy administration $[4,11]$ (Table 1).

In Oberg et al.'s report [6], the response rate was $14 \%$ and OS was 7.5 months, which was short. In contrast, Aoki et al. [4] reported that a long-term SD condition was maintained for patients receiving high STZ dose therapy, such as weekly administrations.

In our case, the disease may have plateaued following the long-term high-dose STZ administration. However, if the patient's condition deteriorated in the future, we plan to switch to a combination therapy.

The second finding was that STZ decreased CA 19-9 levels. In our case, CA 19-9 levels normalized twice: once, in the early stage of administration and second, after one year. A previous report [6] revealed that 5-hydroxyindoleacetic acid levels decreased following STZ administration, but CA 19-9 levels did not.

CA 19-9 levels alone may not reflect the disease state, and the mechanism underlying the decrease in CA 19-9 levels remains unknown, although STZ may have resulted in decreasing CA 19-9 levels. An octreotide scan is a method specific for NET. In this method, indium 111labeled pentetreotide is intravenously injected, and a scan is performed twice, after 4 and 24 h. It was included in the national insurance indication in Japan in 2015. In Japan, there are limited hospitals that perform indium-111-labeled pentetreotide imaging, and our hospital is not one of them. Performing octreotide scans frequently in daily practice is not practical. In addition, a chromometric A measurement is not insurance certified. CA 19-9 level measurement and contrast-enhanced CT can be performed in most hospitals and thus are better to conduct on a daily basis compared with Octreoscan, which should be performed only when an abnormality is observed. 
In conclusion, for unresectable duodenal NET, such as in our case, first, STZ should be administered as a high volume/single dose, with the aim to stabilize the disease state. However, if the disease progresses, switching to a combination therapy may be effective in obtaining long-term prognosis of the patient. In addition, CA19-9 levels may be an effective method of determining the therapeutic effect of STZ in NET with other metastases.

\section{Statement of Ethics}

The authors have no ethical conflicts to disclose.

\section{Disclosure Statement}

The authors have no conflicts of interest to declare.

\section{References}

1 Yao JC, Hassan M, Phan A, Dagohoy C, Leary C, Mares JE, et al. One hundred years after "carcinoid": epidemiology of and prognostic factors for neuroendocrine tumors in 35,825 cases in the United States. J Clin Oncol. 2008 Jun;26(18):3063-72.

2 Hauso 0, Gustafsson BI, Kidd M, Waldum HL, Drozdov I, Chan AK, et al. Neuroendocrine tumor epidemiology: contrasting Norway and North America. Cancer. 2008 Nov;113(10):2655-64.

3 Ito T, Igarashi H, Nakamura K, Sasano H, Okusaka T, Takano K, et al. Epidemiological trends of pancreatic and gastrointestinal neuroendocrine tumors in Japan: a nationwide survey analysis. J Gastroenterol. 2015 Jan;50(1):58-64.

4 Aoki T, Kokudo N, Komoto I, Takaori K, Kimura W, Sano K, et al. Streptozocin chemotherapy for advanced/metastatic well-differentiated neuroendocrine tumors: an analysis of a multi-center survey in Japan. J Gastroenterol. 2015 Jul;50(7):769-75.

5 Moertel CG, Hanley JA. Combination chemotherapy trials in metastatic carcinoid tumor and the malignant carcinoid syndrome. Cancer Clin Trials. 1979;2(4):327-34.

6 Oberg K, Norheim I, Lundqvist G, Wide L. Cytotoxic treatment in patients with malignant carcinoid tumors. Response to streptozocin-alone or in combination with 5-FU. Acta Oncol. 1987;26(6):429-32.

7 Turner NC, Strauss SJ, Sarker D, Gillmore R, Kirkwood A, Hackshaw A, et al. Chemotherapy with 5fluorouracil, cisplatin and streptozocin for neuroendocrine tumours. Br J Cancer. 2010 Mar;102(7):1106-12.

8 Frilling A, Modlin IM, Kidd M, Russell C, Breitenstein S, Salem R, et al.; Working Group on Neuroendocrine Liver Metastases. Recommendations for management of patients with neuroendocrine liver metastases. Lancet Oncol. 2014 Jan;15(1):e8-21.

9 Engstrom PF, Lavin PT, Moertel CG, Folsch E, Douglass HO Jr. Streptozocin plus fluorouracil versus doxorubicin therapy for metastatic carcinoid tumor. J Clin Oncol. 1984 Nov;2(11):1255-9.

10 Bukowski RM, Johnson KG, Peterson RF, Stephens RL, Rivkin SE, Neilan B, et al. A phase II trial of combination chemotherapy in patients with metastatic carcinoid tumors. A Southwest Oncology Group Study. Cancer. 1987 Dec;60(12):2891-5.

11 Oberg K, Norheim I, Alm G. Treatment of malignant carcinoid tumors: a randomized controlled study of streptozocin plus 5-FU and human leukocyte interferon. Eur J Cancer Clin Oncol. 1989 Oct;25(10):1475-9.

12 Sun W, Lipsitz S, Catalano P, Mailliard JA, Haller DG; Eastern Cooperative Oncology Group. Phase II/III study of doxorubicin with fluorouracil compared with streptozocin with fluorouracil or dacarbazine in the treatment of advanced carcinoid tumors: Eastern Cooperative Oncology Group Study E1281. J Clin Oncol. 2005 Aug;23(22):4897-904.

13 Dahan L, Bonnetain F, Rougier P, Raoul JL, Gamelin E, Etienne PL, et al.; Digestive Tumors Group of the Fédération Nationale des Centres de Lutte Contre le Cancer (FNCLCC). Phase III trial of chemotherapy using 


\section{Case Reports in Oncology}

Case Rep Oncol 2019;12:14-21

DOI: $10.1159 / 000496017$

(C) 2019 The Author(s). Published by S. Karger AG, Basel www.karger.com/cro

Miyagawa et al.: Streptozocin Monotherapy for Duodenal NET

5-fluorouracil and streptozotocin compared with interferon alpha for advanced carcinoid tumors: FNCLCCFFCD 9710. Endocr Relat Cancer. 2009 Dec;16(4):1351-61.

14 Meyer T, Qian W, Caplin ME, Armstrong G, Lao-Sirieix SH, Hardy R, et al. Capecitabine and streptozocin \pm cisplatin in advanced gastroenteropancreatic neuroendocrine tumours. Eur J Cancer. 2014 Mar;50(5):90211.

15 Schnedl WJ, Ferber S, Johnson JH, Newgard CB. STZ transport and cytotoxicity. Specific enhancement in GLUT2-expressing cells. Diabetes. 1994 Nov;43(11):1326-33.

16 Helliwell PA, Richardson M, Affleck J, Kellett GL. Regulation of GLUT5, GLUT2 and intestinal brush-border fructose absorption by the extracellular signal-regulated kinase, p38 mitogen-activated kinase and phosphatidylinositol 3-kinase intracellular signalling pathways: implications for adaptation to diabetes. Biochem J. 2000 Aug;350(Pt 1):163-9.

17 Lamarca A, Elliott E, Barriuso J, Backen A, McNamara MG, Hubner R, et al. Chemotherapy for advanced nonpancreatic well-differentiated neuroendocrine tumours of the gastrointestinal tract, a systematic review and meta-analysis: A lost cause? Cancer Treat Rev. 2016 Mar;44:26-41.

18 Moertel CG, Hanley JA, Johnson LA. Streptozocin alone compared with streptozocin plus fluorouracil in the treatment of advanced islet-cell carcinoma. N Engl J Med. 1980 Nov;303(21):1189-94.

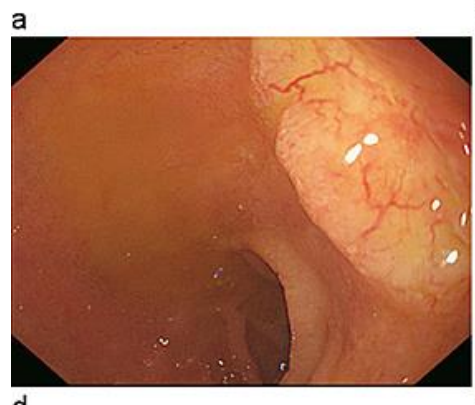

b

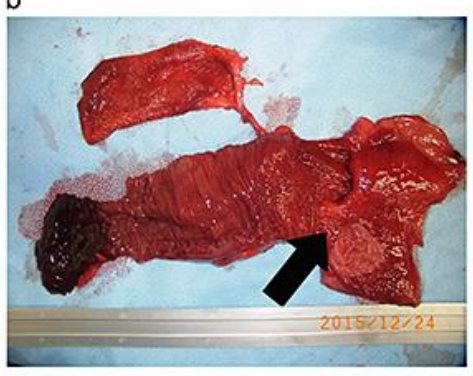

e
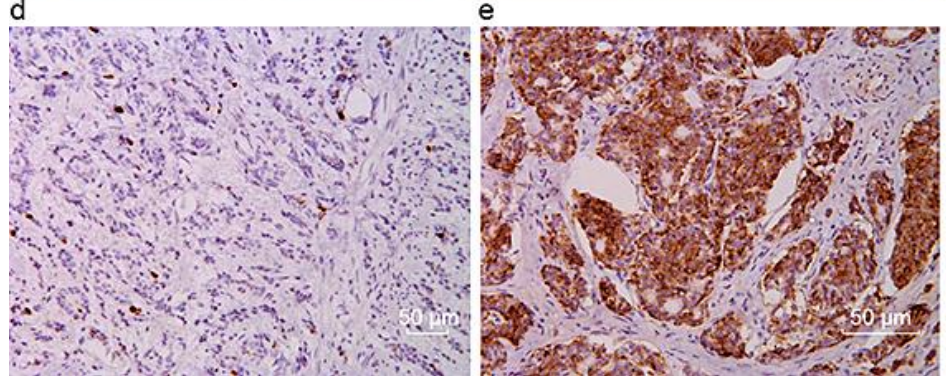

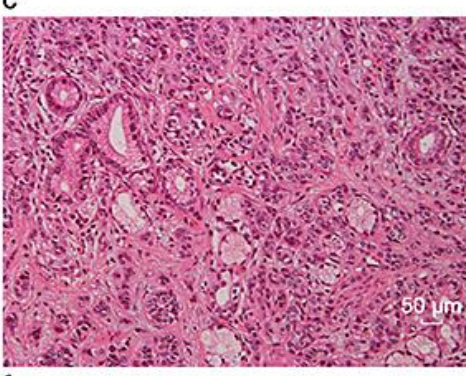

$f$

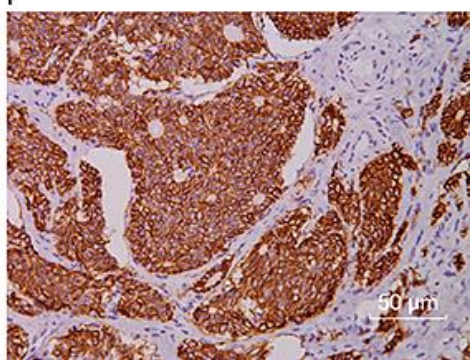

Fig. 1. a, Upper endoscopic examination: the tumor size was $8 \mathrm{~mm}$ on the duodenal bulb. $\mathbf{b}$, Pancreaticoduodenectomy was performed: the black arrow indicates the tumor. c. The tumor comprises small-sized cells with granular eosinophilic cytoplasm, central round nuclei, coarse-clustered chromatin and inconspicuous nuclei (hematoxylin and eosin stain, $\times 200$ ). Immunohistochemical staining. The tumor cells show a Ki-67 index of approximately $5 \%$ (d) with positive expressions for chromogranin A (e) and synaptophysin (f). 


\section{Case Reports in Oncology}

Case Rep Oncol 2019;12:14-21

DOI: $10.1159 / 000496017$

(C)

(c) 2019 The Author(s). Published by S. Karger AG, Basel www.karger.com/cro

Miyagawa et al.: Streptozocin Monotherapy for Duodenal NET

a

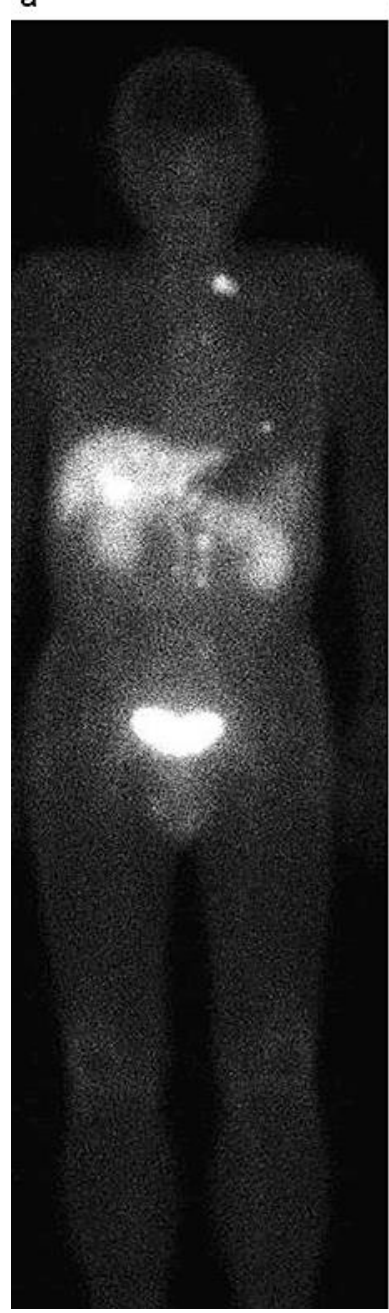

b

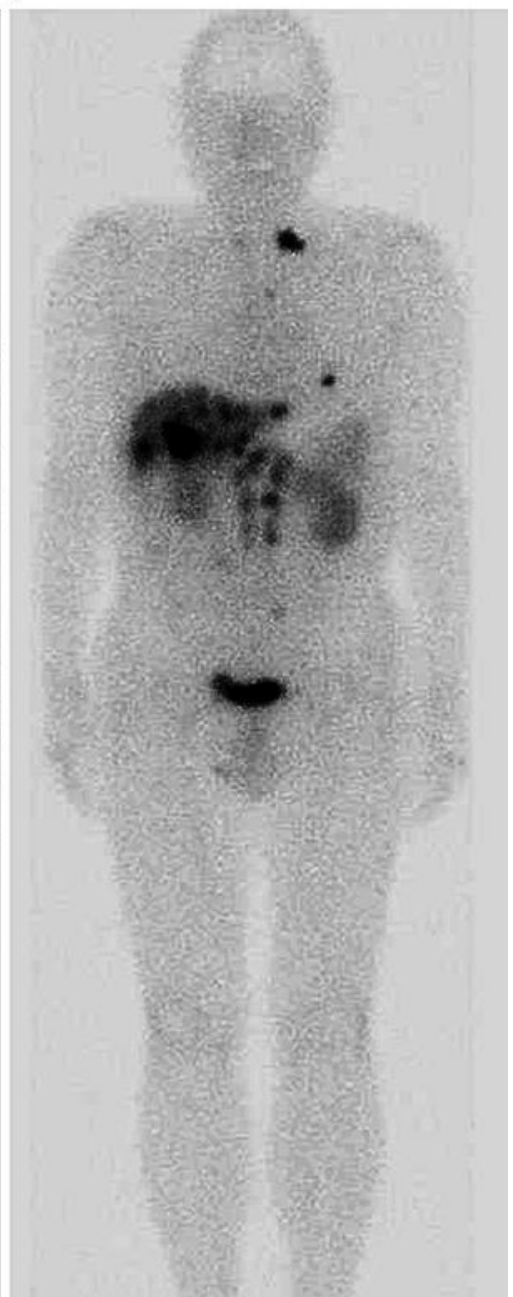

Fig. 2. Octreoscan: comparison 1 year after administration of streptozocin monotherapy before (a) and after 42 courses (b). 


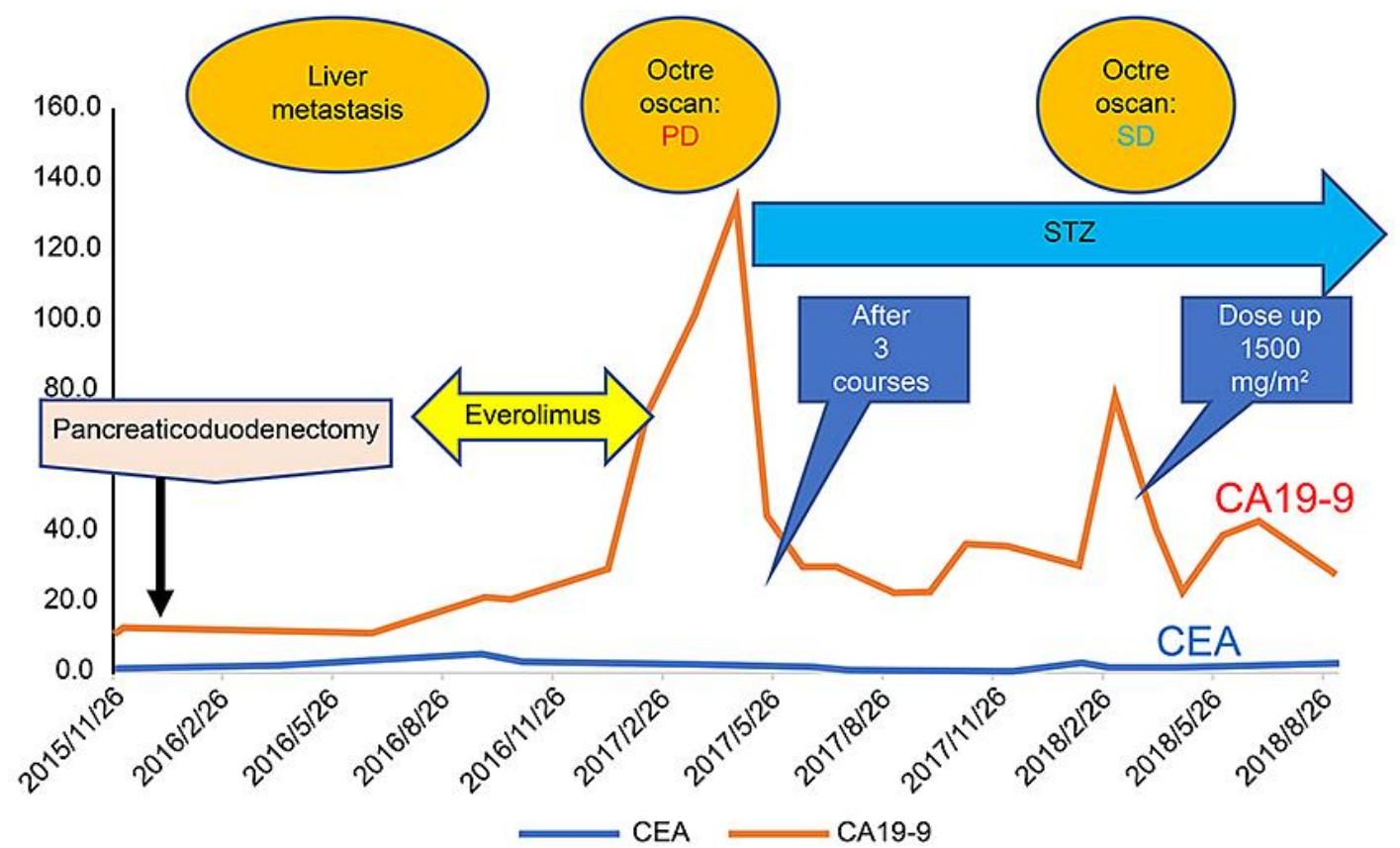

Fig. 3. Treatment course. 
Table 1. Report on the administration of streptozocin to the gastrointestinal tract NET

\begin{tabular}{|c|c|c|c|c|c|c|}
\hline Author year & Year & $n$ & Regimen & ORR (\%) & PFS (m) & OS (m) \\
\hline Moertel [5] & 1979 & $\begin{array}{l}47 \\
42\end{array}$ & $\begin{array}{l}\mathrm{STZ}^{* 1}+\mathrm{CPA} 1,000 \mathrm{mg} / \mathrm{m}^{2} \\
\mathrm{STZ}{ }^{* 1}+5-\mathrm{FU} 400 \mathrm{mg} / \mathrm{m}^{2} / \text { day }\end{array}$ & $\begin{array}{l}24(10 / 42) \\
21(8 / 38)\end{array}$ & - & $\begin{array}{l}12.5 \\
11.2\end{array}$ \\
\hline Engstrom [9] & 1984 & $\begin{array}{r}104 \\
91\end{array}$ & $\begin{array}{l}\mathrm{STZ}^{* 1}+5-\mathrm{FU} 400 \mathrm{mg} / \mathrm{m}^{2} / \text { day } \\
\text { DOX } 60 \mathrm{mg} / \mathrm{m}^{2}\end{array}$ & & $\begin{array}{l}7.8(31 \mathrm{w}) \\
6.5(26 \mathrm{w})\end{array}$ & $\begin{array}{l}16.0(64 w) \\
12.0(48 w)\end{array}$ \\
\hline Bukowski [10] & 1987 & 65 & $\begin{array}{l}\text { History of heart disease }(+) \\
\text { STZ } 400 \text { or } 600 \mathrm{mg} / \mathrm{m}^{2} \text { day } 1 \text {, day } 8 \\
\text { History of heart disease }(-) \\
\text { STZ } 200 \text { or } 400 \mathrm{mg} / \mathrm{m}^{2} \text { day } 1 \text {, day } 8\end{array}$ & & - & 7.6 \\
\hline Oberg [6] & 1987 & $\begin{array}{r}7 \\
24\end{array}$ & $\begin{array}{l}\mathrm{STZ}^{* 1} \\
\mathrm{STZ}{ }^{* 1}+5-\mathrm{FU} 400 \mathrm{mg} / \mathrm{m}^{2} / \text { day }\end{array}$ & $\begin{array}{l}14(1 / 7) \\
8(2 / 24)\end{array}$ & - & $\begin{array}{l}7.5 \\
18\end{array}$ \\
\hline Oberg [15] & 1989 & $\begin{array}{l}10 \\
10\end{array}$ & $\begin{array}{l}\mathrm{STZ}^{* 1}+5-\mathrm{FU} 400 \mathrm{mg} / \mathrm{m}^{2} / \text { day } \\
\text { IFN }\end{array}$ & $\begin{array}{r}0(0 / 10) \\
50(5 / 10)\end{array}$ & - & - \\
\hline Sun [12] & 2005 & $\begin{array}{l}78 \\
85\end{array}$ & $\begin{array}{l}\mathrm{STZ}^{* 1}+5 \text {-FU } 400 \mathrm{mg} / \mathrm{m}^{2} / \text { day } \\
\text { DOX } 40 \mathrm{mg} / \mathrm{m}^{2}+5 \text {-FU } 400 \mathrm{mg} / \mathrm{m}^{2} / \text { day }\end{array}$ & $\begin{array}{l}15(12 / 78) \\
13(11 / 85)\end{array}$ & $\begin{array}{l}5.3 \\
4.5\end{array}$ & $\begin{array}{l}24.3 \\
15.7\end{array}$ \\
\hline Dahan [13] & 2009 & $\begin{array}{l}32 \\
32\end{array}$ & $\begin{array}{l}\mathrm{STZ}^{* 1}+5-\mathrm{FU} 400 \mathrm{mg} / \mathrm{m}^{2} / \text { day } \\
\mathrm{IFN}\end{array}$ & $\begin{array}{l}3(1 / 32) \\
9(3 / 32)\end{array}$ & $\begin{array}{r}5.5 \\
14.1\end{array}$ & $\begin{array}{l}30.4 \\
44.3\end{array}$ \\
\hline Turner [7] & 2010 & 9 & $\begin{array}{l}\mathrm{STZ} 1,000 \mathrm{mg} / \mathrm{m}^{2} / \text { day } \\
+5-\mathrm{FU} 500 \mathrm{mg} / \mathrm{m}^{2} / \text { day + CDDP }\end{array}$ & $22(2 / 9)$ & - & - \\
\hline Aoki [4] & 2011 & $\begin{array}{l}4 \\
4\end{array}$ & $\begin{array}{l}\text { Daily*3 or Weekly*4 (STZ mono) } \\
\text { Daily*3 or Weekly*4 (UFT,5FU combination) }\end{array}$ & $\begin{array}{l}25(1 / 4) \\
25(1 / 4)\end{array}$ & $\begin{array}{l}- \\
-\end{array}$ & - \\
\hline Meyer [14] & 2014 & $\begin{array}{l}9 \\
8\end{array}$ & $\begin{array}{l}\mathrm{STZ}^{* 1}+\mathrm{CAP} \\
\mathrm{STZ}{ }^{* 1}+\mathrm{CAP}+\mathrm{CDDP}\end{array}$ & $6(1 / 17)$ & - & - \\
\hline
\end{tabular}

STZ, streptozocin; 5-FU, fluorouracil; DOX, doxorubicin; CPA, cyclophosphamide; CAP, capecitabine; CDDP, cisplatin; IFN, interferon- $\alpha$. *1: Daily, $500 \mathrm{mg} / \mathrm{m}^{2} /$ day (1 course for 6 weeks, except for the studies of Engstrom et al. [9] and Sun et al. [12], in which 1 course was administered for 10 weeks. *2: 1 course 3 weeks, maximum 6 cycle. *3: Day 1-5. *4: 1,000 $\mathrm{mg} / \mathrm{body} /$ week, or $1,000 \mathrm{mg} /$ body/2 weeks. 